See Article page 663.

\section{Commentary: Chronic kidney disease and coronary bypass surgery: Getting it right}

\author{
Hani Ali-Ghosh, MBBS, FRCS (CTh), and \\ Clifford William Barlow, FRCS (CTh), DPhil
}

It is incumbent upon surgeons to deliver the correct treatment or operation, targeted to each individual patient. In the context of coronary bypass grafting (CABG) surgery, the evidence for a survival advantage of patients with complex coronary artery disease is growing, ${ }^{1,2}$ particularly in specific subgroups such as those with diabetes. ${ }^{3}$ Chronic kidney disease (CKD) is prevalent in patients with arteriosclerosis and/or diabetes who present with coronary artery disease and is a known risk factor for CABG. ${ }^{4,5}$ It is not clear whether this increased perioperative risk limits the treatment effect of CABG.

Doenst and colleagues ${ }^{6}$ assess the influence of CKD on 10 -year mortality and cardiovascular (CV) outcomes in patients with ischemic heart failure. They undertook a secondary analysis of data from the Surgical Treatment for Ischemic Heart Failure (STICH) trial, which randomized systolic heart failure patients to $\mathrm{CABG}$ and medical therapy versus medical therapy alone, and showed a survival advantage for patients also having $\mathrm{CABG}^{7}$ Baseline estimated glomerular filtration rates (eGFRs) were calculated and the 1209 patients, randomized to medical therapy or CABG in the STICH trial, were categorized as CKD stages 1 through 5. Stage 1: eGFR $>90 \mathrm{~mL} / \mathrm{min}(\mathrm{n}=232)$, stage 2: eGFR 60 to $89 \mathrm{~mL} / \mathrm{min}(\mathrm{n}=646)$, stage 3: eGFR 30 to $59 \mathrm{~mL} / \mathrm{min}$ $(\mathrm{n}=303)$ and stage 4 and 5 : eGFR $<30 \mathrm{~mL} / \mathrm{min}(\mathrm{n}=28)$. Baseline characteristics of patients in the 2 treatment arms were equal for each CKD stage. However, patients in CKD stages 3 through 5 were older than those in stages 1 and 2

From the Department of Cardiothoracic Surgery, University Hospital Southampton, Southampton, United Kingdom.

Disclosures: Authors have nothing to disclose with regard to commercial support.

Received for publication March 10, 2020; revisions received March 10, 2020; accepted for publication March 10, 2020; available ahead of print March 31, 2020. Address for reprints: Clifford William Barlow, FRCS (CTh), DPhil, Department of Cardiothoracic Surgery, University Hospital Southampton, Tremona Rd, Southampton SO16 6YD, United Kingdom (E-mail: cliffbarlow@ hotmail.com).

J Thorac Cardiovasc Surg 2022;163:674-5

0022-5223/\$36.00

Crown Copyright $(2020$ Published by Elsevier Inc. on behalf of The American Association for Thoracic Surgery

https://doi.org/10.1016/j.jtcvs.2020.03.051

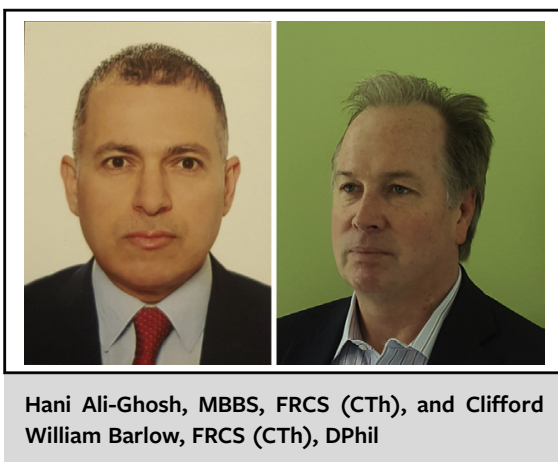

CENTRAL MESSAGE

Mild-to-moderate chronic kidney

disease does not appear to in-

fluence the long-term survival

benefit of coronary bypass

surgery.

(aged 66-71 vs 54-59 years) and had more comorbidities. There was an inverse association linear relationship between eGFR and risk of death, $\mathrm{CV}$ death, and/or CV rehospitalization (all $P$ values $<.001$ ). The study's primary outcome showed a significant improvement in 10-year survival and $\mathrm{CV}$ rehospitalization rates by CABG in CKD stages 1 through 3. These data were inconclusive in CKD stages 4 and 5, probably due to small sample size.

There is limited evidence, mainly based on retrospective database analyses, on whether CKD affects the treatment benefit of CABG ${ }^{8,9}$ Although this is a secondary analysis of the STICH trial, Doenst and colleagues ${ }^{6}$ demonstrate, for the first time using data from a randomized prospective study, that mild-to-moderate CKD does not appear to influence the long-term benefit of CABG. There are important limitations, such as limited patient numbers in the highest and lowest CKD stages. In addition, because the STICH trial was not powered for interaction testing, residual confounding cannot truly be excluded. Finally, any conclusions apply in mild-to-moderate CKD only and are in patients with heart failure with reduced ejection fraction.

In real-life practice, the presence of CKD may be a predictor for not referring patients for surgery. ${ }^{10}$ Although this could be challenged by the results of the study by Doenst and colleagues, ${ }^{6}$ more information is required before a recommendation for CABG treatment can be made in all otherwise-suitable CKD patients. These effects should be confirmed regardless of left ventricular ejection fraction and for patients with more severe grades of CKD who are 
presumably the least likely to be referred for surgery. In addition, off-pump surgery and new pharmaceutical measures $^{11}$ that may further enhance the benefits of CABG in patients with CKD will require investigation. Nevertheless, Doenst and colleagues ${ }^{6}$ provide further impetus in the importance of establishing the correct treatment for the right patient.

\section{References}

1. Head SJ, Milojevic M, Daemen J, Ahn JM, Boersma E, Christiansen EH, et al. Mortality after coronary artery bypass grafting versus percutaneous coronary intervention with stenting for coronary artery disease: a pooled analysis of individual patient data. Lancet. 2018;391:939-48.

2. Sipahi I, Akay MH, Dagdelen S, Blitz A, Alhan C. Coronary artery bypass grafting vs percutaneous coronary intervention and long-term mortality and morbidity in multivessel disease: meta-analysis of randomized clinical trials of the arterial grafting and stenting era. JAMA Intern Med. 2014;174:223-30.

3. Farkouh ME, Domanski M, Sleeper LA, Siami FS, Dangas G, Mack M, et al. Strategies for multivessel revascularization in patients with diabetes. $N$ Engl $J$ Med. 2012;367:2375-84.

4. Doenst T, Wijeysundera D, Karkouti K, Zechner C, Maganti M, Rao V, et al. Hyperglycemia during cardiopulmonary bypass is an independent risk factor for mortality in patients undergoing cardiac surgery. J Thorac Cardiovasc Surg. 2005; $130: 1144$
5. Ranucci M, Castelvecchio S, Menicanti L, Frigiola A, Pelissero G. Risk of assessing mortality risk in elective cardiac operations: age, creatinine, ejection fraction, and the law of parsimony. Circulation. 2009;119:3053-61.

6. Doenst T, Haddad H, Stebbins A, Hill JA, Velazquez JE, Lee KL, et al. Renal function and coronary bypass surgery in patients with ischemic heart failure. J Thorac Cardiovasc Surg. 2022;163:664-72.e3.

7. Velazquez EJ, Lee KL, Jones RH, Al-Khalidi HR, Hill JA, Panza JA, et al. Coronary-artery bypass surgery in patients with ischemic cardiomyopathy. $N$ Engl $J$ Med. 2016;374:1511-20

8. Bangalore S, Guo Y, Samadashvili Z, Blecker S, Xu J, Hannan EL. Everolimuseluting stents or bypass surgery for multivessel coronary disease. $N$ Engl J Med. 2015;372:1213-22.

9. Roberts JK, Rao SV, Shaw LK, Gallup DS, Marroquin OC, Patel UD. Comparative efficacy of coronary revascularization procedures for multivessel coronary artery disease in patients with chronic kidney disease. Am J Cardiol. 2017;119: 1344-51.

10. Ram E, Goldenberg I, Kassif Y, Segev A, Lavee J, Einhorn-Cohen M, et al Real-life characteristics and outcomes of patients who undergo percutaneous coronary intervention versus coronary artery bypass grafting for left main coronary artery disease: data from the prospective Multi-vessel Coronary Artery Disease (MULTICAD) Israeli Registry. Eur J Cardiothorac Surg. 2018;54: 717-23.

11. Demirjian S, Ailawadi G, Polinsky M, Bitran D, Silberman S Shernan SK, et al. Safety and tolerability study of an intravenously administered small interfering ribonucleic acid (siRNA) post on-pump cardiothoracic surgery in patients at risk of acute kidney injury. Kidney Int Rep. 2017;2:836-43. 